\title{
Nutritional impact of antipseudomonas intravenous antibiotic courses in cystic fibrosis
}

P Vic, S Ategbo, F Gottrand, V Launay, G A Loeuille, J C Elian, D Druon, J P Farriaux, D Turck

\begin{abstract}
Objective-To evaluate the short term effects on nutritional status of home intravenous anti-pseudomonas antibiotic courses in cystic fibrosis (CF) patients chronically colonised with Pseudomonas aeruginosa.

Design-A prospective study involving 38 CF patients, mean age 10.9 (SD 4.3) years (range 4.3 to 22.2 years), presenting with pulmonary exacerbations of $P$ aeruginosa infection. The patients received a 14 day antibiotic course of intravenous ceftazidime $(200 \mathrm{mg} / \mathrm{kg} / \mathrm{day})$ and either amikacin (35 mg/kg/day) or tobramycin $(15 \mathrm{mg} / \mathrm{kg}$ ) day). Nutritional evaluation on days 1 and 14 involved measurements of weight, weight/height ratio (per cent of predicted value), energy intake (per cent of recommended daily allowances), serum prealbumin, and body composition assessed by two methods: bioelectrical analysis (BIA) and skinfold anthropometry. The nonparametric Wilcoxon $t$ test was used for statistical analysis, with a Bland-Altman plot to assess the degree of agreement between the two methods of evaluating body composition.
\end{abstract}

Results-Weight increased by $1.0(0.8) \mathrm{kg}$ (p < 0.001); weight/height increased from 94.4(12.2)\% to $98(12.7) \%(p<0.001)$, energy intake from $107(32) \%$ to $119(41) \%$ $(\mathrm{p}<0.02)$, and prealbumin from $183(63)$ to $276(89) \mathrm{mg} / \mathbf{1}(\mathrm{p}<0.001)$. Fat mass increased by $0.8(1.0) \mathrm{kg}(\mathrm{p}<0.001)$, without any significant change in fat-free mass. The limits of agreement between BIA and anthropometry were $-0.7 \mathrm{~kg}$ and $+1.1 \mathrm{~kg}$.

Conclusions-Antibiotic courses allow an improvement in nutritional status in CF patients, with a gain in fat mass.

(Arch Dis Child 1997;76:437-440)

Keywords: cystic fibrosis; antibiotics; anthropometry; bioelectrical analysis

Maintenance of good nutritional status is known to be an important prognostic factor in cystic fibrosis patients. Lung function, and morbidity and mortality from pulmonary exacerbations, are influenced by nutritional status. ${ }^{1}$ However, the impact of antipseudomonas antibiotic courses on nutritional status has not been thoroughly investigated. Previous studies were mainly focused on the influence of antibiotics on resting energy expenditure ${ }^{2}$ and on the influence of nutritional supplements during antibiotic treatment on protein metabolism. ${ }^{3}$ Both studies involved hospital inpatients. To our knowledge, there is no information on the amount and nature of weight gain after home intravenous antibiotic treatment for exacerbations of pseudomonas infection in cystic fibrosis patients. Our aim was to evaluate the early effects of such treatment on nutritional status in a population of children, adolescents, and young adults with cystic fibrosis who were chronically colonised with Pseudomonas aeruginosa.

\section{Methods}

POPULATION

The study was approved by the Lille University Hospital ethics committee. Written consent of the patient or the parents, or both, was required before enrolment in the study. From October 1993 to June 1995, 38 cystic fibrosis patients aged 10.9 (SD 4.3) years (range 4.3 to 22.2 years) were included: 18 girls aged 10.5 (4.0) years and 20 boys aged 11.2 (4.6) years. The diagnosis of cystic fibrosis was confirmed by at least two abnormal sweat tests (sweat chloride $>60 \mathrm{mmol} / \mathrm{l}$ ). All patients had chronic pulmonary colonisation by $P$ aeruginos $a$, defined by at least three positive bacteriological examinations of the sputum over a period of at least six months. They presented with pulmonary exacerbations, defined as an increase in cough, sputum production, shortness of breath, and weight loss. ${ }^{4}$

Twenty eight CF patients were followed at the Lille University Hospital Cystic Fibrosis Centre and seven and three respectively at the Dunkirk and Camiers City Hospital Cystic Fibrosis Centres.

\section{PROCEDURES}

Patients received intravenous antipseudomonas antibiotics - ceftazidime (200 $\mathrm{mg} / \mathrm{kg} / \mathrm{d})(\mathrm{n}=38)$ and either amikacin (35 $\mathrm{mg} / \mathrm{kg} / \mathrm{d})(\mathrm{n}=20)$ or tobramycin $(15 \mathrm{mg} / \mathrm{kg} / \mathrm{d})$ ( $n=18$ )-according to the sensitivities of the strains of $P$ aeruginosa found in the sputum. Treatment was given for 14 days; the first day was spent in hospital, after which the children were discharged. For the study, patients were readmitted for 24 hours on day 14. Adjuvant treatment remained unchanged during antibiotic treatment (physiotherapy, pancreatic enzymes, and vitamins) and no specific dietetic recommendations were given. The patients did not receive parenteral or enteral nutritional support. 
Table 1 Body composition changes between day 1 and day 14. Values are means (SD)

\begin{tabular}{llll}
\hline & Day 1 & Day 14 & $p$ \\
\hline Weight (kg) & $30.2(13)$ & $31.2(13)$ & $<0.001$ \\
FM-A (kg) & $4.7(3.5)$ & $5.5(4.1)$ & $<0.001$ \\
FM-I (kg) & $5(3.7)$ & $5.7(3.9)$ & $<0.001$ \\
FFM-A (kg) & $25.5(10.5)$ & $25.8(10.8)$ & 0.2 \\
FFM-I (kg) & $25(10.9)$ & $25.3(10.0)$ & 0.2 \\
\hline
\end{tabular}

FM-A = fat mass evaluated by anthropometry; FM-I = fat mass evaluated by impedance measurement; FFM-A = fat-free mass evaluated by anthropometry; FFM-I = fat-free mass evaluated by impedance measurement.

No statistical difference was found on day 1 and day 14 between FM-A and FM-I and between FFM-A and FFM-I.

Nutritional evaluation was performed on day 1 (before the start of antibiotics) and on day 14 (the last day of antibiotics). Patients were weighed in the fasting state using the same scales. Weight to height ratio was measured and expressed as a percentage of the predicted value for age, sex, and height. ${ }^{5}$ Energy intake, expressed as the percentage of recommended daily allowances (RDA), ${ }^{6}$ was evaluated by a questionnaire to parents and children about food intake the day before. Serum prealbumin was measured. Anthropometric measurements were made by two physicians (PV and SA) using a Harpenden caliper (Holtain, Crymmich, United Kingdom). The following skinfolds were assessed on the non-dominant side of the body: prebicipital, retrotricipital, subscapular, and suprailiac. Three measurements were performed on each side and the mean value of each skinfold calculated. The percentage of fat mass was derived from these mean values using the equations of $\mathrm{Brook}^{7}$ for children younger than 14 and Durnin et $a l^{8}$ for the older patients. Fat-free mass was determined by subtracting body fat mass from body weight. Body composition analysis was also performed by bioelectrical impedance analysis (BIA) (BIA 101, RLJ Systems, Detroit, MI, USA; $50 \mathrm{kHz}$ ). BIA measures body impedance, which is inversely proportional to the volume of total body water. Assuming that fat mass is free of water, fat-free mass can be calculated using age specific predictive equations worked out by BIA systems and validated by comparison with a reference method. We used the equation of Schaefer et al, ${ }^{9}$ which correlates the fat-free mass with the resistance index calculated by dividing the square of the subject's height by the body impedance. Fat mass was then calculated by subtracting fat-free mass from body weight.

Erythrocyte sedimentation rate (ESR) and the polymorphonuclear neutrophil cell count were also measured on days 1 and 14 . Forced vital capacity (FVC), forced expiratory volume in one second $\left(\mathrm{FEV}_{1}\right)$, and forced expiratory flow between $25 \%$ and $75 \%$ of FVC $\left(\mathrm{FEF}_{25-75}\right)$ were measured on days 1 and 14 using a portable spirometer (Respiradyne II Plus, Model 5-7930P; Sherwood Medical, St Louis, MO, USA). Results were expressed as a percentage of predicted values for age, sex, and height.

The non-parametric Wilcoxon signed rank test for paired samples was used to compare data between days 1 and 14 . The statistical method described by Bland and Altman ${ }^{10}$ was used to assess the degree of agreement between
BIA and anthropometry to evaluate body composition. All results are expressed as mean (SD).

\section{Results}

Weight gain was observed in all patients: weight increased from 30.2 (13) $\mathrm{kg}$ on day 1 to 31.2 (13) $\mathrm{kg}$ on day $14(\mathrm{p}<0.001)$; weight/height ratio increased from $94.4(12.2) \%$ (range $73.6-$ $128.6 \%$ ) on day 1 to $98.0(12.7) \%$ (range $77.3-130.2 \%)$ on day $14(\mathrm{p}<0.001)$. Energy intake increased from $107(32) \%$ of RDA to $119(41) \%(\mathrm{p}<0.02)$. Prealbumin concentrations increased from 183 (63) $\mathrm{mg} / 1$ to 276 (89) $\mathrm{mg} / \mathrm{l}(\mathrm{p}<0.001)$. Inflammatory markers improved, with a decrease in ESR from 15 (20) $\mathrm{mm}$ (range $2-180 \mathrm{~mm}$ ) on day 1 to $9(21) \mathrm{mm}$ (range $1-40 \mathrm{~mm})$ on day $14(\mathrm{p}<0.001)$, and a decrease in neutrophil count from 6671 (3524) per $\mathrm{mm}^{3}$ (range $1900-16400$ ) on day 1 to 3558 (1408) (range 2080-8800) on day 14 (p $<0.001)$. Spirometric indices also improved from days 1 to 14 : FVC increased from $65(17) \%$ to $79(15) \%(\mathrm{p}<0.01), \mathrm{FEV}_{1}$ increased from $58(20) \%$ to $72(18) \%$ (p < 0.01 ), and $\mathrm{FEF}_{25-75}$ increased from $37(16) \%$ to $52(18) \%(\mathrm{p}<0.001)$.

Body composition changes are summarised in table 1: for both methods used, an increase in fat mass of $0.8(1.0) \mathrm{kg}$ was found, without any significant change in fat-free mass. Using the Bland-Altman method, comparison of the two methods (BIA and anthropometry) showed a difference of $0.2(0.45) \mathrm{kg}$ for fat-free mass on day 1. Therefore the limits of agreement were $-0.7 \mathrm{~kg}$ and $+1.1 \mathrm{~kg}$. The same limits of agreement were found on day 14. No difference was observed between patients receiving amikacin or tobramycin.

\section{Discussion}

Although calculation of fat-free mass and fat mass using BIA has not been fully evaluated in cystic fibrosis, our study confirms that the analysis of body composition by BIA is useful and agrees with anthropometry in cystic fibrosis patients, with limits of agreement of $-0.7 \mathrm{~kg}$ and $+1.1 \mathrm{~kg}$. This means that fat-free mass evaluated by BIA may be $0.7 \mathrm{~kg}$ below or $1.1 \mathrm{~kg}$ above the value evaluated by anthropometry in $95 \%$ of our cystic fibrosis patients, with a mean difference of $0.2 \mathrm{~kg}$. Similar differences were shown by Borowitz and Conboy in adult cystic fibrosis patients ${ }^{11}$ and by Spicher et al in children with cystic fibrosis. ${ }^{12}$ Azcue et al recently validated the use of BIA in cystic fibrosis by comparing it with the isotopic distribution of $\mathrm{H}_{2}{ }^{18} \mathrm{O} \cdot{ }^{13} \mathrm{BIA}$ is a rapid, painless, portable, and reliable method of estimating body composition. In contrast to anthropometry, measurements do not depend on the experience of the physician. Our data show that BIA can be used routinely in cystic fibrosis patients to evaluate nutritional status and assess the effects of antibiotic courses.

In this particular study, we did not include an untreated control group. It is well known that in patients presenting with pulmonary pseudomonas colonisation, lung function dete- 
riorates in the absence of antibiotic treatment. Szaff et al showed that frequent antibiotic treatment against pseudomonas improves survival and quality of life in cystic fibrosis patients chronically colonised with $P$ aeruginosa, although permanent eradication of the organism is rarely obtained. ${ }^{14}$ This observation makes the inclusion of an untreated control group impossible on ethical grounds.

Nutritional management is also an important prognostic factor, a clear association between malnutrition and deteriorating lung function having been shown. ${ }^{15}$ Consensus reports recommend an energy intake of 120 $150 \%$ of RDA in cystic fibrosis patients. ${ }^{16-18} \mathrm{We}$ focused our work on the short term effects of antibiotics on nutritional status. It is known that antipseudomonas antibiotics allow weight gain $^{23}$ as shown in our patients who had a significant increase in weight to height ratio. Steinkamp et al also observed a weight gain of $0.9 \mathrm{~kg}$ after a 15 day antibiotic treatment course in 29 cystic fibrosis patients. ${ }^{2}$ In another study, which was devoted to the effects of nutritional supplementation during the management of pulmonary exacerbations in cystic fibrosis patients, Shepherd et $a l^{3}$ reported a weight gain of $1.2 \mathrm{~kg}$ in the non-supplemented group, but without providing any information on which body compartment was involved in the gain. In this group, no change was observed in net protein repartition, thus suggesting that weight gain might have been caused by fat increase. Moreover their study was carried out in hospital, in contrast to ours which was mainly conducted at home. It is now very unusual to give intravenous antibiotic courses in hospital, except for patients with poor respiratory status. This makes our results more apposite. The fact that weight gain was mainly fat, as shown by the two methods in our study, is very important since it demonstrates a real nutritional improvement and rules out a variation in water or sodium balance induced by the antibiotic infusions. The increase in prealbumin concentrations also confirmed that short term nutritional status improved.

There are two factors which may explain this improvement in nutritional status:

(1) Energy intake increased from $107 \%$ to $119 \%$ of RDA, although no specific dietetic recommendations were given to the patients or their parents before or during antibiotic treatment and no nutritional support was given. Patients were treated at home, and their nutritional habits did not change during the two week treatment period; the distribution between protein, lipid, and carbohydrate intakes did not change either (data not shown). This strongly suggests that nutritional improvement was due to an increase in energy intake but not to qualitative changes in the meals. The patients continued their daily activities (school attendance), so we think a reduction in their physical activity during antibiotic treatment was unlikely. A decrease in inflammation, as shown by the decrease in ESR and neutrophil count, may lead to a better appetite during and shortly after antibiotics because of decreased synthesis of cytokines such as cachectin-tumour necrosis factor and interleukin 1. These peptides are released by immunocompetent cells in inflammation and are responsible for a reduction in dietary intake. ${ }^{19}$ Suter et al found increased plasma concentrations of these cytokines in cystic fibrosis patients admitted to hospital for pulmonary exacerbations. ${ }^{20}$

(2) Energy needs in cystic fibrosis patients are greater than in healthy children because of an increase in resting energy expenditure. ${ }^{21-24}$ This increase has been shown to be inversely correlated with pulmonary function and nutritional status. ${ }^{2}$ In our study, antibiotics improved both nutritional status and respiratory function, and it is very likely that they caused a decrease in resting energy expenditure, as recently shown by other investigators. ${ }^{25} \mathrm{Im}$ proving energy intake and decreasing resting energy expenditure allows conservation of energy in the form of fat mass.

Our study shows the beneficial effect of antipseudomonas antibiotics on nutritional status in cystic fibrosis patients chronically colonised with $P$ aeruginosa. However, from the data reported it is not possible to determine whether this effect is only a catch up in nutritional status previously impaired by the pulmonary exacerbation, or if antibiotic courses could have a long term beneficial effect on the nutritional status of cystic fibrosis patients. Prolonged nutritional studies are needed to answer this question.

This study was supported by the Association Française de Lutte contre la Mucoviscidose and the French Ministry of Health. We are indebted to the nursing staff of Lille, Dunkirk, and Camiers Hospitals for their help during the study.

1 Corey M, McLaughlin FJ, Williams M. A comparison of survival, growth and pulmonary function in patients with cystic fibrosis in Boston and Toronto. 7 Clin Epidemiol 1988;41:588-93.

2 Steinkamp G, Drommer A, Von der Hardt H. Resting energy expenditure before and after treatment for Pseudomonas aeruginosa infection in patients with cystic fibrodomonas aeruginosa infection in patic

3 Sis. Am f Clin Nutr 1993;57:685-9. Francis P. Short-term nutritional supplementation during management of pulmonary exacerbations in cystic fibrosis: management of pulmonary exacerbations in cystic fibrosis:

f Clin Nutr 1988;48:235-9.
4 Smith AL, Ramsey B, Redding G, Haas J. Endobronchial infection in cystic fibrosis patients. Acta Paediatr Scand Suppl 1989;363:31-6.

5 Sempe M, Pedron G, Roy-Pernot MF. In: Théraplix A, ed. Auxologie. Méthodes et séquences. Paris: Printel, 1979

6 Dupin H, Abraham J, Giachetti I. Apports nutritionnels conseillés pour la population française. 2nd Ed. Paris: Tec and Doc, 1994.

7 Brook CGD. Determination of body composition of children from skinfold measurements. Arch Dis Child 1971; 46:182-4.

8 Durnin JVGA, Rahaman MM. The assessment of the amount of fat in the human body from measurement of the skinfold thickness. Br $\mathcal{F}$ Nutr 1967;21:681-9.

9 Schaefer F, Georgi M, Zieger A, Scharer K. Usefulness of bioelectric impedance and skinfold measurements in bioelectric impedance and skinfold measurements in
predicting fat-free mass derived from total body potassium in children. Pediatr Res 1994;35:617-24.

10 Bland JM, Altman DG. Statistical methods for assessing agreement between two methods of clinical measurement. Lancet 1986;i:307-10.

11 Borowitz D, Conboy K. Are bioelectrical impedance measurements valid in patients with cystic fibrosis? $\mathcal{F}$ Pediatr Gastroenterol Nutr 1994;18:453-6.

12 Spicher V, Roulet M, Schaffner C, Schutz Y. Bio-electrical impedance analysis for estimation of fat-free mass and muscle mass in cystic fibrosis patients. Eur $\mathcal{F}$ Pediatr 1993; 152:222-5.

13 Azcue $M$, Fried M, Pencharz PB. Use of bioelectrical impedance analysis to measure total body water in patients with cystic fibrosis. F Pediatr Gastroenterol Nutr 1993;16: with cysti 440 .

14 Szaff M, Hoiby N, Flensborg W. Frequent antibiotic therapy improves survival of cystic fibrosis patients with chronic 
Pseudomonas aeruginosa infection. Acta Paediatr Scand 1983;72:651-7.

15 Kraemer R, Rudeberg A, Hadorn B, Rossi E. Relative underweight in cystic fibrosis and its prognosis value. Acto Paediatr Scand 1978;67:33-7.

16 Gaskin KJ. The impact of nutrition in cystic fibrosis: a review. F Pediatr Gastroenterol Nutr 1988;7(suppl 1):S1217.

17 Dodge JA. Nutritional requirements in cystic fibrosis: a review. F Pediatr Gastroenterol Nutr 1988;7(suppl 1):S8-11

18 Ramsey BW, Farrell PM, Pencharz P, and the Consensus Committee. Nutritional assessment and management in cystic fibrosis: a consensus report. Am f Clin Nutr 1992;55: 108-16.

19 Keusch GT. Malnutrition, infection and immune function. In: Suskind RM, Lewinter-Suskind L, eds. The malnourished child. New York: Raven Press, 1990:37-59.

20 Suter S, Schaad VB, Roux-Lombard P, Girardin E, Grau G, Dayer JM. Relation between tumor necrosis factor-alpha and granulocyte elastase- alpha 1-proteinase inhibitor complexes in the plasma of patients with cystic fibrosis. Am Rev Respir Dis 1989;140:1640-4.

21 Girardet JP, Tounian P, Sardet A, et al. Resting energy expenditure in infants with cystic fibrosis. F Pediatr Gastroenterol Nutr 1994;18:214-9.

22 Bowler IM, Green JH, Wolfe SP, Littlewood JM. Resting energy expenditure and substrate oxidation rates in cystic fibrosis. Arch Dis Child 1993;68:754-9.

23 Grunow JE, Azcue MP, Berrall G, Pencharz PB. Energy expenditure in cystic fibrosis during activity of daily living. f Pediatr 1993;122:243-6.

24 Vaisman N, Pencharz PB, Corey M, Canny GJ, Hahn E. Energy expenditure of patients with cystic fibrosis. $\mathcal{F}$ Pediatr 1987;111:496-500.

25 Naon H, Hack S, Shelton MT, Gotthoffer RC, Gozal D. Resting energy expenditure. Evolution during antibiotic treatment for pulmonary exacerbation in cystic fibrosis. treatment for pulmonary
Chest 1993;103:1819-25. 